\title{
The hybrid strategy: Too little too early and too much too late?
}

\author{
Sanjiv K. Gandhi, MD
}

See related article on pages 1102-10.

Rahkonen and colleagues ${ }^{1}$ from the Hospital for Sick Children in Toronto present a very comprehensive analysis of pulmonary artery stenosis and growth in children undergoing hybrid single ventricle palliation. The authors should be congratulated on a very instructive article that will definitely add to the knowledge base regarding this complex group of children.

The theoretical benefits of the hybrid procedure relate to the avoidance of cardiopulmonary bypass and circulatory arrest in the neonatal period. However, the authors have demonstrated a disturbingly high rate of pulmonary artery issues related to the hybrid approach, potentially influencing Fontan procedure candidacy as well as carrying implications for long-term Fon$\tan$ procedure outcomes. The high number of interstage mortalities, although not believed to be related to pulmonary artery issues, is also concerning and does not support the notion that the hybrid approach results in a more stable circulation than the standard Norwood approach. Interestingly, the authors demonstrated that it is not merely the pulmonary artery banding that results in pulmonary artery problems, but perhaps the performance of a simultaneous damus-kaye-stansel anastomosis and a glenn procedure that may create an anatomic milieu unfavorable for optimal left pulmonary artery growth, because patients undergoing hybrid palliation who subsequently undergo biventricular repair or cardiac transplantation do not experience the same pulmonary artery growth issues. The high number of reinterventions for pulmonary artery problems, involving $50 \%$ of patients following stage 2 , with the attendant need for general anesthesia and the potential morbidity associated with each intervention, certainly must be considered in the comprehensive treatment algorithm of these children. Again, the main purported benefit of the hybrid approach is the elimination of a neonatal pump run; although this has theoretical downsides, neonatal cardiopulmonary bypass is well tolerated and widely used for many different diagnoses. Although the selection of a standard Norwood operation versus the hybrid operation was not randomized in this series, the authors do provide limited data on a contemporaneous cohort of children who underwent the Norwood

\footnotetext{
From the Department of Pediatric Cardiothoracic Surgery, British Columbia Children's Hospital, Vancouver, British Columbia, Canada.

Disclosures: Author has nothing to disclose with regard to commercial support.

Received for publication Dec 17, 2014; accepted for publication Dec 20, 2014; available ahead of print Jan 25, 2015.

Address for reprints: Sanjiv K. Gandhi, MD, Department of Pediatric Cardiothoracic Surgery, British Columbia Children's Hospital, 4480 Oak St, Ste AB307, Vancouver,

BC, Canada V7V 1 Y8 (E-mail: sgandhi@cw.bc.ca).

J Thorac Cardiovasc Surg 2015;149:1111

$0022-5223 / \$ 36.00$

Copyright (C) 2015 by The American Association for Thoracic Surgery http://dx.doi.org/10.1016/j.jtcvs.2014.12.047
}

operation. Comparative statistical analysis is not provided, but it seems clear that the standard Norwood approach is not associated with the same degree of pulmonary artery grief in the longer term. Even if the rate of successful Fontan completion is the same between the hybrid and Norwood groups, the presence of a stented left pulmonary artery will inevitably lead to even more pulmonary artery interventions and perhaps more Fontan-related morbidity in the future.

There are many obvious questions raised by this study. How does the pulmonary artery growth with hybrid palliation compare with the standard Norwood pathway in the long term? Should impaired pulmonary artery growth with hybrid palliation change our opinion about this procedure? Which patients should undergo hybrid procedures versus Norwood procedures? Undoubtedly, even in patients who undergo successful Fontan completion, those with suboptimal pulmonary artery growth will be more prone to the development of later Fontan complications. The Sick Kids group, ${ }^{2}$ as well as other authors ${ }^{3,4}$ have published comparative results between the Norwood and hybrid strategies and have demonstrated equivalent survival after stage 2 palliation and following Fontan completion. However, there is little objective information to establish the superiority of the hybrid strategy. Additional comparative data with traditional patients is necessary to answer the fundamental question of which palliative stream is optimal for patients with a single ventricle. In this series, excluding the bridge to transplant, bridge to biventricular repair, and salvage patients, survival to stage 2 was $62.9 \%$; in the Single Ventricle Reconstruction trial $^{5}$ survival to stage 2 was $73 \%$. Inherent with the hybrid procedure are several unique morbidities, namely dealing with the atrial septum, the potential need for reverse shunts to provide retrograde flow to the aortic arch, and the pulmonary artery growth and stenosis issues well delineated in this article. Does the hybrid approach merely delay and magnify morbidity to later stages of palliation? The Hospital for Sick Children is 1 of few that performs both the Norwood and hybrid procedures without selection bias, an approach that is optimal for comparing the 2 strategies.

\footnotetext{
References

1. Rahkonen O, Chaturvedi R, Benson L, Honjo O, Caldarone CA, Lee KJ. Pulmonary artery stenosis in hybrid single-ventricle palliation: High incidence of left pulmonary artery intervention. J Thorac Cardiovasc Surg. 2015;149:1102-10.e2.

2. Baba K, Kotani Y, Chetan D, Chaturvedi RR, Lee KJ, Benson LN. Hybrid versus Norwood strategies for single-ventricle palliation. Circulation. 2012;126(Suppl):S123-31.

3. Davies RR, Radtke WA, Klenk D, Pizarro C. Bilateral pulmonary arterial banding results in an increased need for subsequent pulmonary artery interventions. $J$ Thorac Cardiovasc Surg. 2014;147:706-12.

4. Dave H, Rosser B, Knirsch W, Hubler M, Pretre R, Kretschmar O. Hybric approach for hypoplastic left heart syndrome and its variants: the fate of the pulmonary arteries. Eur J Cardiothorac Surg. 2014;46:14-9.

5. Ohye RG, Sleeper LA, Mahony L, Newburger JW, Pearson GD, Lu M, et al. Comparison of shunt types in the Norwood procedure for single-ventricle lesions. $N$ Engl J Med. 2010;362:1980-92.
} 